\title{
(9)
}

\author{
Álvaro Pastor Escribano* \\ Adrián Laredo Argumosa*
}

\section{EL IMPACTO DE LA COVID-19 EN LA ECONOMÍA MEXICANA}

La crisis de 2020 originada por la COVID-19 puede considerarse como una crisis única por su origen, características, magnitud y consecuencias. La pandemia ha generado un doble shock de oferta y demanda, inducido por las restricciones impuestas por las autoridades para proteger a la población que, previsiblemente, provocará la mayor recesión sufrida por México en su historia reciente. Para compensar esta contracción, las autoridades han aplicado una política económica levemente expansiva, sin perder de vista la estabilidad presupuestaria y de precios. Pese al elevado grado de incertidumbre y las dificultades existentes, se puede observar una clara reactivación de la economía a partir del tercer trimestre. Si México consigue aprovechar sus fortalezas, cabe esperar que esta recuperación continúe en 2021.

Palabras clave: México, coronavirus, pandemia, crisis, indicadores macroeconómicos, indicadores de coyuntura, política económica, perspectivas.

Clasificación JEL: H12, O53.

\section{Introducción}

El objetivo de este artículo es realizar un breve análisis de la COVID-19 en México y sus múltiples efectos socioeconómicos. Para ello, en primer lugar, se expone la evolución de la epidemia. En segundo lugar se examina su impacto económico, prestando atención a la evolución de distintos indicadores de coyuntura y macroeconómicos, al impacto a nivel sectorial y a las diversas medidas de política económica aplicadas. En un tercer apartado se recogen

\footnotetext{
* Oficina Económica y Comercial de España en México. Las opiniones expresadas solo comprometen a sus autores. Versión de noviembre de 2020.

DOI: https:/doi.org/10.32796/bice.2020.3130.7134
}

las principales perspectivas para la economía mexicana en 2020 y 2021. Y para finalizar se concluye indicando los principales retos y oportunidades con que cuenta México para superar esta crisis.

\section{Evolución de la COVID-19 en México}

La pandemia de la COVID-19 se ha convertido en una crisis sanitaria, económica y social a escala global sin precedentes. En México se distinguen dos fases, tanto desde un punto de vista sanitario como social: una fase de crecimiento continuado del número de contagios y, a partir del mes de junio, una fase de estabilización. 
Desde los primeros casos importados el 29 de febrero, y teniendo en cuenta la experiencia con la pandemia H1N1 de 2009, las autoridades mexicanas establecen una serie de medidas de prevención (lavado de manos, quedarse en casa y uso de mascarilla en caso de enfermedad) y un procedimiento de detección del virus para evitar la propagación por todo el país. Debido a la dispersión comunitaria del virus, el 24 de marzo se implementan una serie de medidas más restrictivas. Merece la pena destacar el distanciamiento social, la suspensión de eventos masivos (superiores a 50 personas) y la suspensión temporal de actividades no esenciales y escolares. Se entienden por actividades esenciales aquellas necesarias para atender la emergencia sanitaria y las fundamentales para la economía, como seguridad pública y conservación de infraestructuras (DOF 31/03/2020). A pesar de estas medidas, debido al contagio comunitario, la suspensión de actividades no esenciales, escolares y de eventos se vuelve indefinida.

En el mes de mayo las autoridades elaboran una estrategia para la reapertura de las actividades sociales, educativas y económicas. Esta estrategia, que se inicia el 1 de junio, está basada en un sistema de semáforos que evalúa semanalmente a nivel estatal el riesgo epidemiológico relacionado con la reapertura de actividades (DOF 14/05/2020). Según este sistema, se establecen determinadas restricciones en función de la ocupación hospitalaria de la red de infección respiratoria aguda grave (IRAG) y de la positividad a la COVID-19:

- Semáforo rojo (ocupación IRAG superior al $71 \%$ o positividad a la COVID-19 superior al $40 \%$ ): solo se permiten las actividades económicas esenciales.

- Semáforo naranja (ocupación IRAG entre el $51 \%$ y el $70 \%$ o positividad a la
COVID-19 entre el $30 \%$ y el $39 \%$ ): se permiten las actividades en espacios públicos abiertos y actividades no esenciales con aforo y operación reducidos.

- Semáforo amarillo (ocupación IRAG entre el $31 \%$ y el $50 \%$ o positividad a la COVID-19 entre el $20 \%$ y el $29 \%$ : se permiten todas las actividades laborales y actividades en espacios públicos abiertos y cerrados con restricciones.

- Semáforo verde (ocupación IRAG menor al $30 \%$ o positividad a la COVID-19 menor al 19\%): sin restricciones.

Entre junio y agosto, todos los estados se han encontrado en semáforo naranja y rojo, siendo Campeche el primer estado que pasa a semáforo amarillo a mediados de agosto. Desde finales de septiembre la mayor parte de estados se encuentran en semáforo naranja y amarillo, a excepción de Campeche, que en septiembre es el primer estado en alcanzar el semáforo verde.

En el Gráfico 1 se puede observar cómo ha sido la evolución de la COVID-19 en México a nivel de casos diarios nuevos registrados y número de fallecimientos en cada fase (media diaria por quincena). Desde finales de febrero y hasta el mes de junio, el aumento de los casos nuevos diarios fue exponencial, y no es hasta finales de julio cuando se alcanza el número máximo de casos nuevos diarios registrados y la curva de contagios comienza a disminuir. Actualmente, México es el undécimo país con más casos confirmados acumulados y el quinto con más muertes (Data Europa, 2020).

Como se puede observar en el Gráfico 2, al igual que en la mayoría de los países occidentales, en México, aunque no hay una respuesta gubernamental hasta finales de marzo de 2020, $D$ 


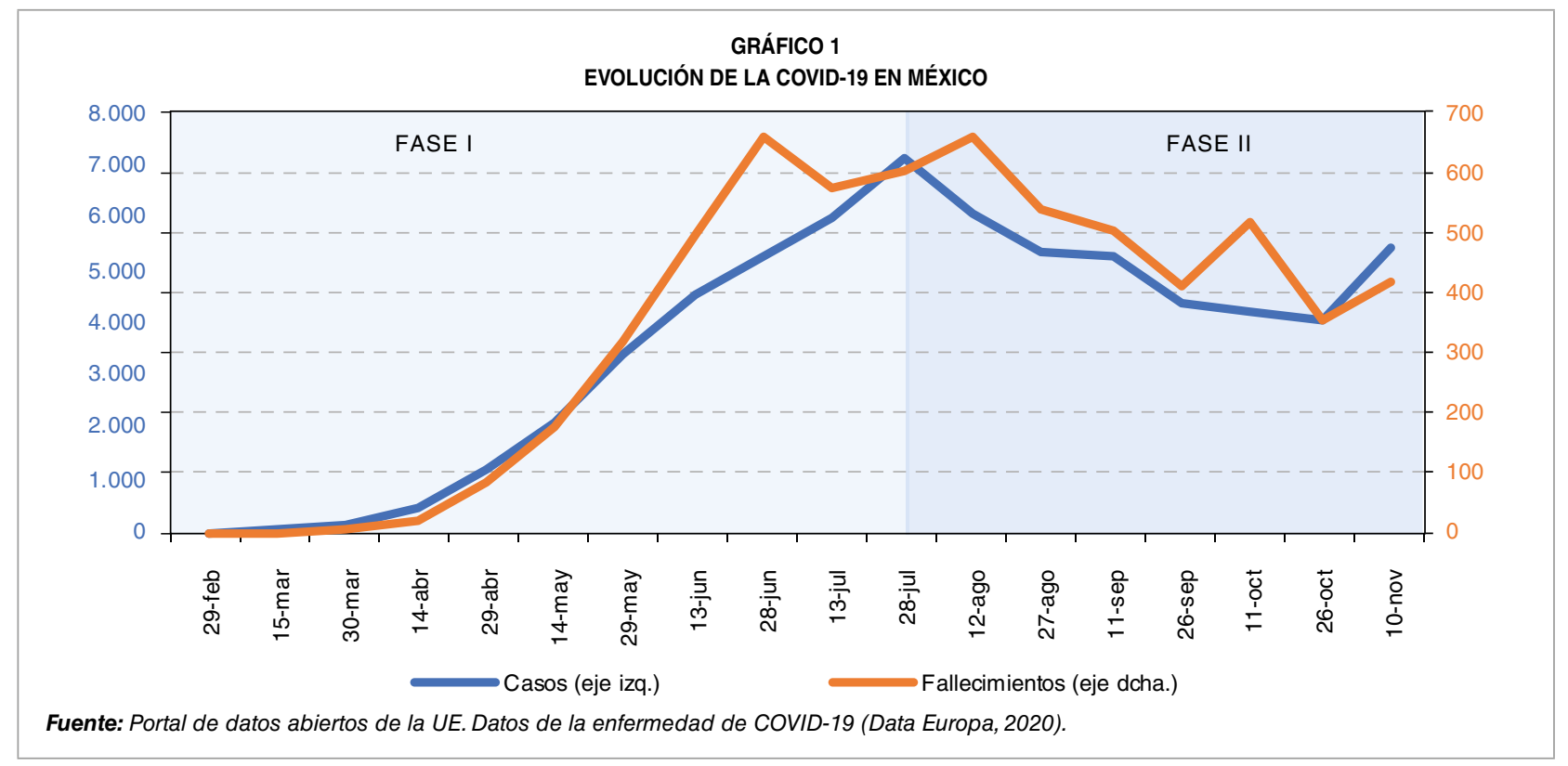

se establecen intensas restricciones en un periodo de tiempo muy corto. El índice de severidad, que representa la dureza de las medidas adoptadas durante la contingencia, hace referencia a nueve indicadores: la suspensión escolar, el cierre de espacios de trabajo, la prohibición de eventos y reuniones públicas, la restricción en el transporte público, el confinamiento en casa, las campañas públicas y el control de movimientos internos y migratorios.

De acuerdo con los datos de la Universidad de Oxford, el índice de severidad en México se encuentra, en octubre, en la media en comparación con otros países de América Latina e incluso por encima de algunos países de Europa y América del Norte.

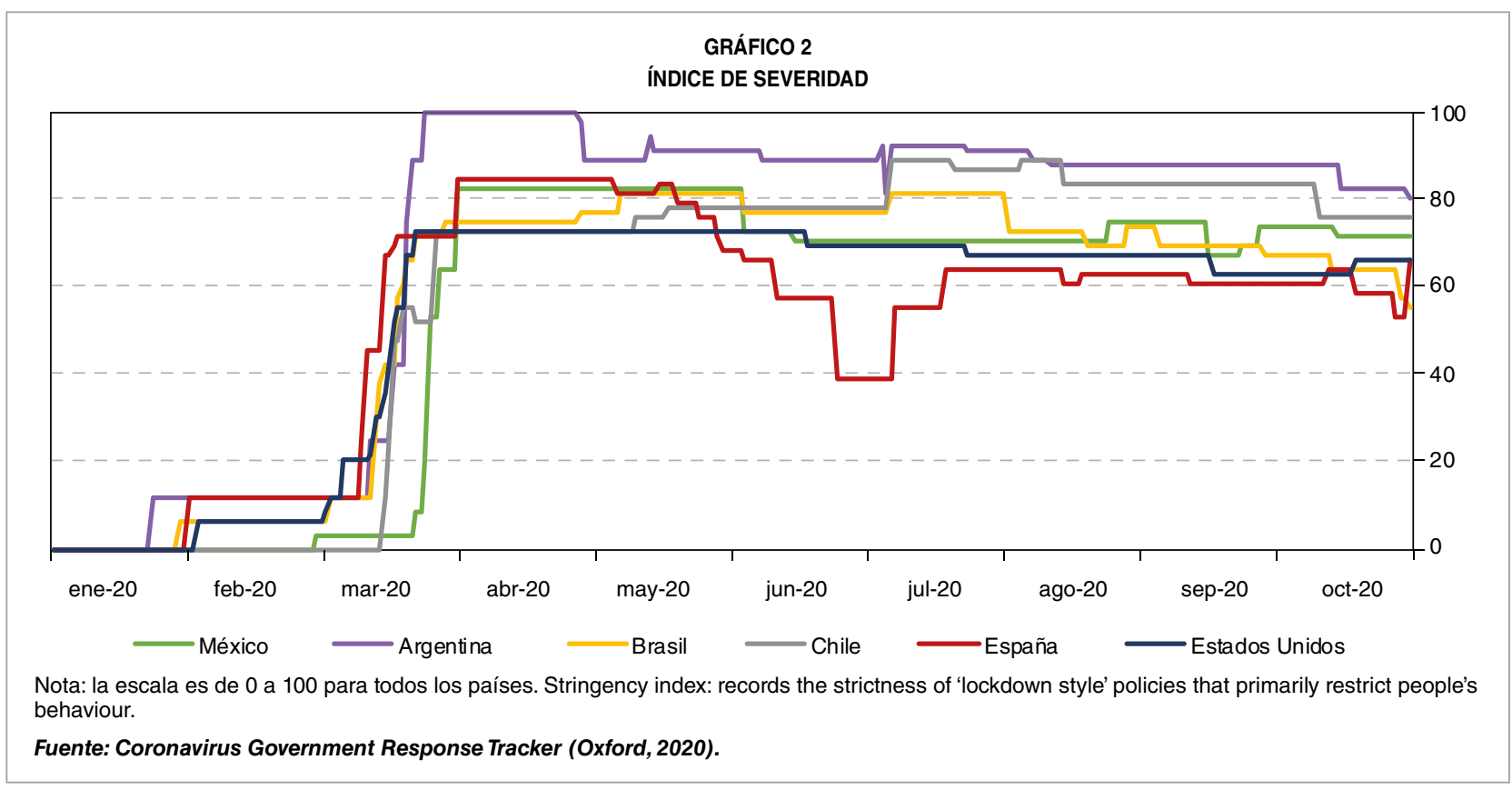




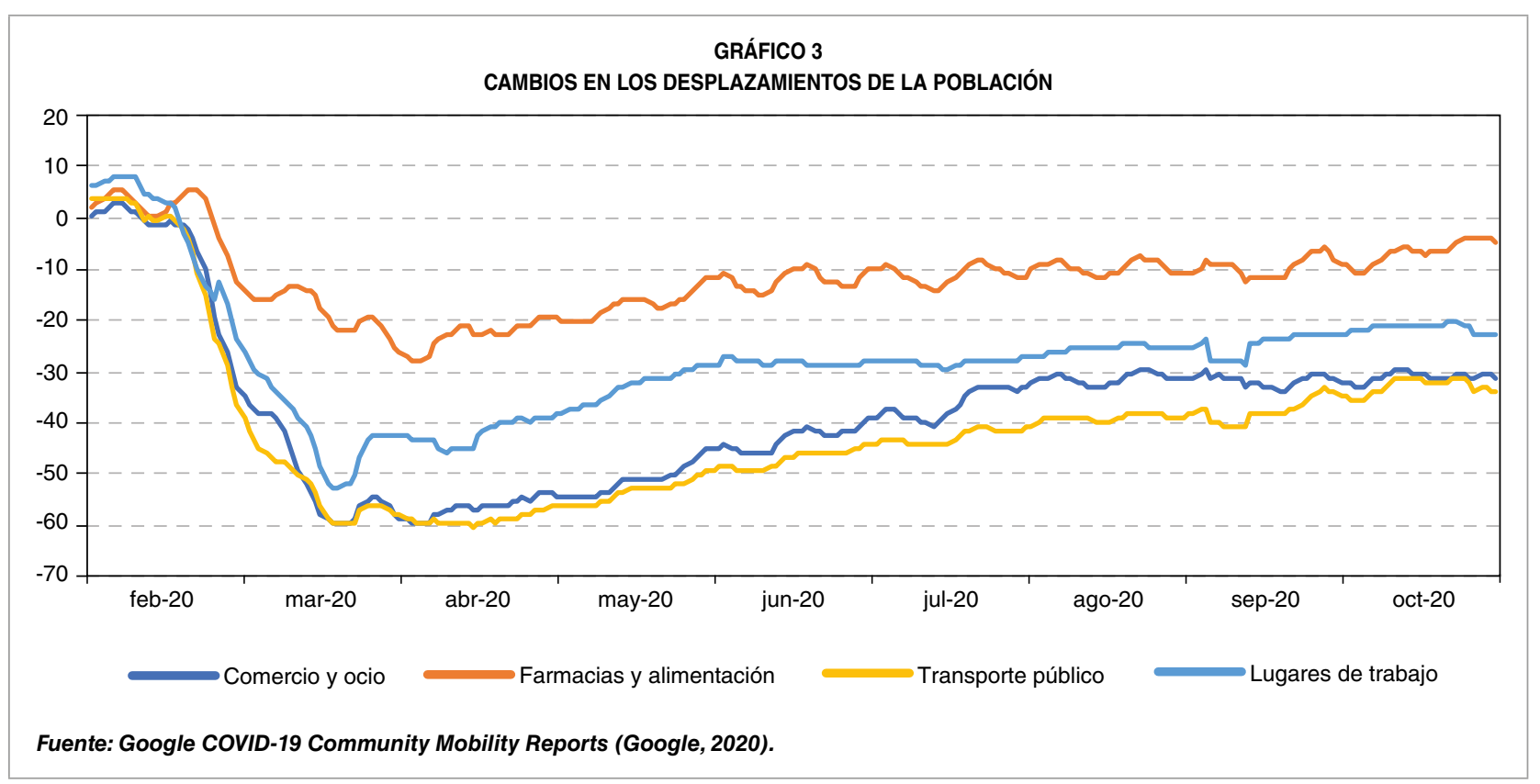

Una de las principales consecuencias sociales de las medidas impuestas debido a la situación de contingencia provocada por la COVID-19 son los cambios de los desplazamientos de la población. En el Gráfico 3 se puede observar cómo han influido las medidas para aplanar la curva de contagios en la movilidad de la población. En abril llegó a verse reducida hasta en un $60 \%$, con respecto a enero de 2020, para transporte público y comercio. Como se aprecia en el gráfico, la movilidad de las personas se ha ido recuperando paulatinamente. Sin embargo, aún se encuentra muy por debajo de los niveles habituales.

En relación con las restricciones a la movilidad, cabe destacar que México, aunque ha recomendado a sus ciudadanos no realizar viajes no esenciales, no ha restringido la salida de nacionales al extranjero ni la entrada de extranjeros en el país. Sin embargo, México sí se ha visto afectado por las restricciones migratorias impuestas por países terceros, incluida la UE. En todo momento ha sido posible realizar viajes esenciales a EE UU.

\section{Impacto de la COVID-19 en la economía mexicana}

\subsection{Actividad económica}

El impacto económico inicial ocasionado por la pandemia del coronavirus es lo que se conoce como un shock de oferta. Debido a las medidas de distanciamiento social implantadas por las autoridades, se produce un paro en la producción, la disrupción de las cadenas globales de valor y el cierre o suspensión de múltiples servicios. A su vez, este shock de oferta produce otro de demanda, ya que la pérdida de actividad económica se traduce en una disminución de ingresos, que resulta en la caída del consumo y de la inversión. Esta dinámica se ve agravada por el alto grado de incertidumbre y por el canal financiero.

En el caso de México, las drásticas medidas de contención tomadas por la COVID-19 han tenido un impacto muy significativo. De acuerdo con la evolución del producto interior bruto (PIB), los efectos económicos en la $\triangleright$ 
economía mexicana pueden dividirse en dos fases.

El impacto económico de la COVID-19 en México se comienza a observar en marzo. A pesar de que el desarrollo de la pandemia en América se hace notar más tarde que en otras regiones del mundo, México se ve afectado inicialmente por las relaciones económicas que tiene con el exterior. El inicio de las medidas de confinamiento en las regiones de Asia y Europa producen importantes disrupciones en las cadenas globales de valor de múltiples sectores manufactureros, en las que México es uno de los países de la región con más participación (BID, 2020). Además de esto, la cancelación de vuelos a escala global y, como se menciona en el apartado anterior, las restricciones migratorias impuestas a México por países terceros impactan muy negativamente al sector turístico.

Asimismo, la actividad económica en México se ve afectada por las medidas impuestas por las autoridades, especialmente por la suspensión de las actividades no esenciales. Los efectos más agudos de la crisis se dejan sentir durante los meses de abril y mayo. Hay que resaltar que, a mediados de mayo, el Consejo de Salubridad General aprueba el retorno de la construcción, minería y fabricación de equipos de transporte al considerarlas actividades esenciales (DOF 14/05/2020). A partir de junio da comienzo una reapertura gradual de las distintas industrias, condicionada por la situación epidémica. Progresivamente, la mayoría de los estados han ido avanzando hacia los semáforos naranja o amarillo.

Este esquema tiene su reflejo en la evolución del PIB en México (Gráfico 4). En el segundo trimestre se puede observar una caída del PIB del $18,7 \%$ con respecto al mismo trimestre del año anterior, liderada por el sector secundario, que cae un $25,7 \%$. Sin embargo, atendiendo al índice global de actividad económica, la actividad más afectada es la de los servicios de alojamiento temporal y de preparación de alimentos y bebidas (dentro del sector terciario), que cae un $70,4 \%$ debido principalmente a la cancelación de vuelos internacionales y a las medidas migratorias adoptadas por terceros países. Abril y mayo son los meses que presentan una caída más pronunciada, del $19,9 \%$ y $22,7 \%$, respectivamente. Como se ha mencionado, gracias a $\square$

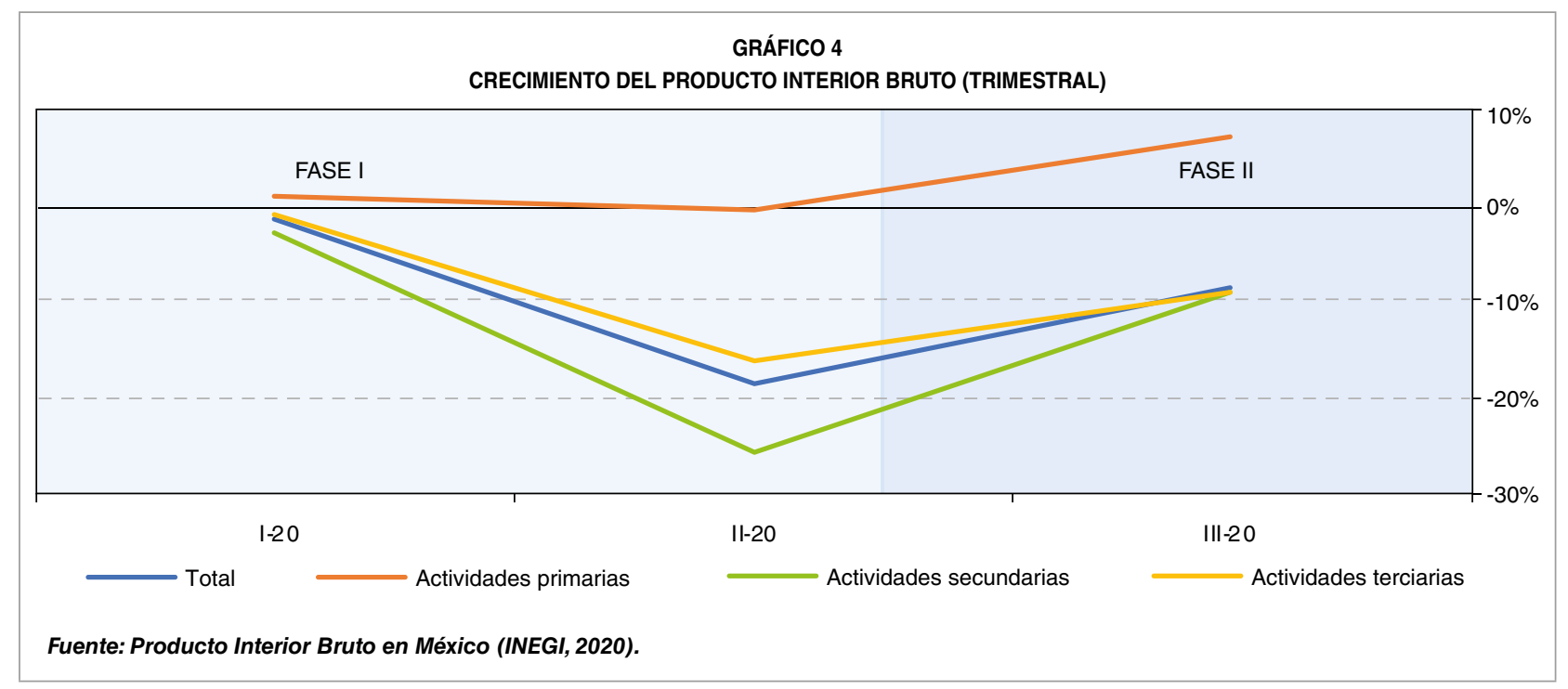


la reapertura de las actividades de construcción, minería y fabricación de equipos de transporte a partir de junio, actividades que representan el $14,7 \%$ del PIB, ya se puede apreciar una cierta recuperación gradual de la actividad económica, que en el tercer trimestre crece un $12 \%$ con respecto al segundo trimestre (Instituto Nacional de Estadística y Geografía —INEGI—, 2020).

\subsection{Indicadores de coyuntura}

Una vez presentada la evolución de la pandemia en México, se hace referencia a indicadores de coyuntura que ilustran la realidad económica generada por la COVID-19. Como la crisis viene producida por un doble shock de oferta y demanda, sus efectos económicos se pueden observar tanto en factores de oferta como de demanda.

Por el lado de la oferta, uno de los principales efectos del confinamiento ha sido la destrucción de empleo. De acuerdo con el Instituto Mexicano del Seguro Social (IMSS), que recoge la evolución del empleo formal del sector privado en México, entre los meses de febrero y julio se perdieron en torno a 1.100 .000 empleos formales, lo que supuso una reducción del 5,4\%. Con la progresiva reactivación del empleo, en septiembre la caída respecto a febrero es del 4,4\% (Gráfico 5). Por su parte, el empleo informal, que representa en torno al $50 \%$ de la población ocupada (INEGI, 2020), llegó a registrar pérdidas de más de diez millones de empleos, equivalente al 27,1\% (Gráfico 6). Con la reapertura se está produciendo una reactivación más rápida del empleo informal, más sensible al ciclo, pero en todo caso aún se sitúa en septiembre un $11,4 \%$ por debajo de su nivel de febrero (ENOE, ETOE, 2020). Los datos del IMSS, además, nos permiten apreciar el impacto sectorial. Así, entre febrero y septiembre, las caídas más pronunciadas se han producido en las actividades de servicios de alojamiento temporal, preparación de alimentos y bebidas, servicios recreativos y de esparcimiento y en la industria del cuero y calzado, que registran caídas superiores al $20 \%$. También hay que señalar que el impacto en la pérdida de empleo ha sido asimétrico en el conjunto de estados que conforman México. Estados con un mayor peso en el sector turístico, como Quintana Roo o Baja California del Sur, son de los más afectados (IMSS, 2020).

Lógicamente, la pérdida de empleo ha llevado a una disminución en los ingresos que, junto con las medidas de distanciamiento social, han producido caídas notables en el consumo. A pesar de que las ventas generales, tanto de comercio al por mayor como al por menor muestran una caída de entre el $24 \%$ y $26 \%$ en los meses de abril y mayo (Gráfico 7 ), hay productos en específico que sufrieron caídas mucho mayores, como es el caso del sector de la automoción (Gráfico 8), en el que las ventas cayeron en torno al $60 \%$ y la producción lo hizo en un $95 \%$ (INEGI, 2020).

A pesar de la paulatina recuperación a partir de junio, se sigue observando un alto grado de incertidumbre, tal y como muestran los indicadores de confianza del consumidor (Gráfico 8) y empresarial (Gráfico 10), que, a pesar de mejorar durante el segundo trimestre, se han estancado en el tercer trimestre (INEGI, 2020). Esta situación de incertidumbre también se puede observar en la evolución de la concesión de créditos al sector privado (Gráfico 11), en el que se ha producido una importante desaceleración (créditos a empresas, $15 \%$ ) e incluso decrecimiento (créditos al consumo, $-3 \%$ ), a pesar de las medidas adoptadas por el Banco de México para facilitar el crédito, que se verán más adelante.

Por último, uno de los riesgos más preocupantes de esta crisis es la profundización de $\triangleright$ 
la pobreza en México, la cual ya presentaba un nivel elevado. De hecho, de acuerdo con CONEVAL (Consejo Nacional de Evaluación de la Política de Desarrollo Social), la pobreza laboral ${ }^{1}$ repuntó del $35,7 \%$ en el primer trimestre de 2020 al $45,8 \%$ en el segundo trimestre.

1 Situación en la que el ingreso laboral no es suficiente para cubrir los costes básicos alimentarios y no alimentarios.
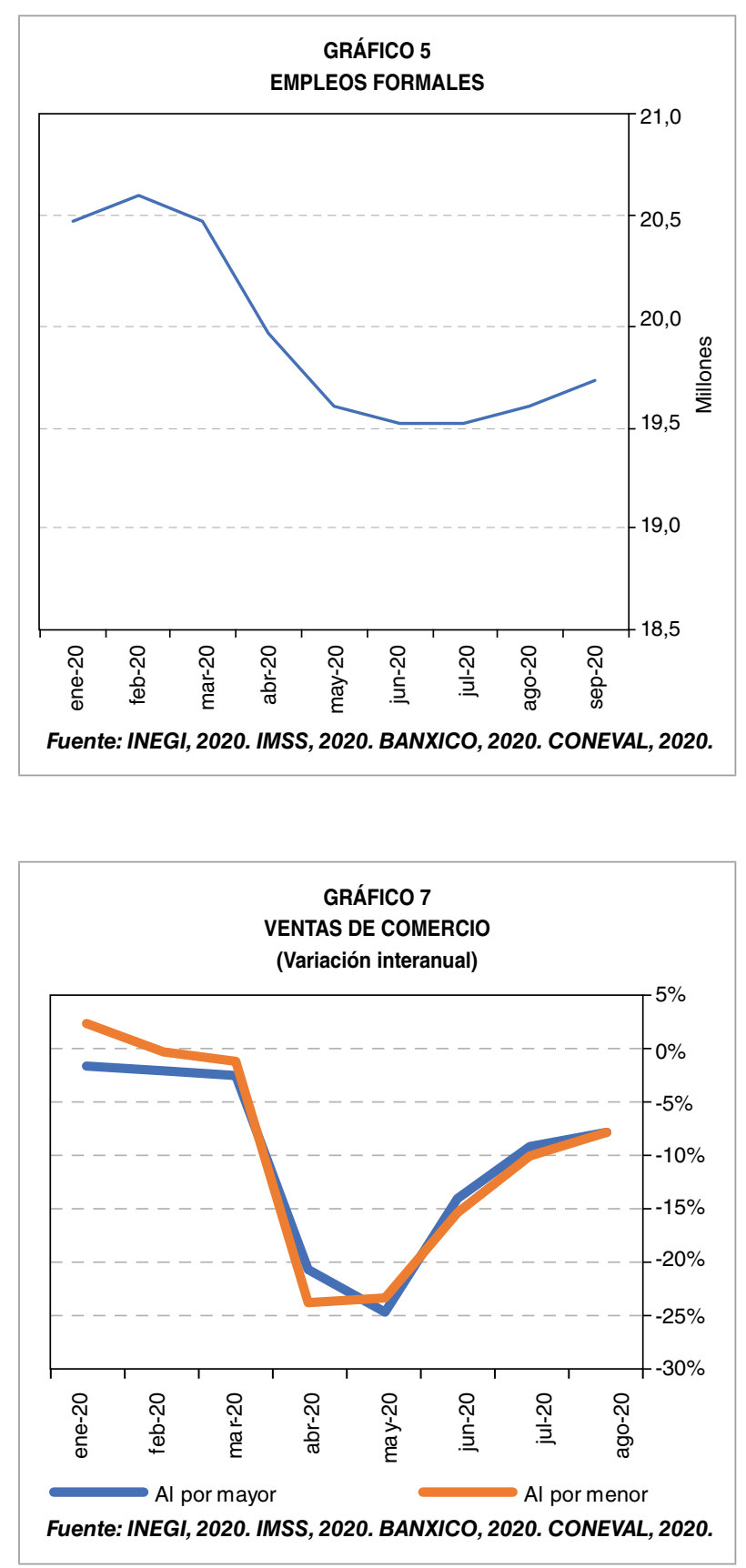

Asimismo, se puede observar que, aunque los salarios de los trabajadores formales han mantenido su dinamismo, posiblemente como consecuencia de un efecto composición, están aumentando en los últimos meses a menor ritmo que el coste de la canasta alimentaria y no alimentaria básica (que determina la línea de pobreza), lo cual sugiere que la pobreza laboral podría estar aumentando (Gráfico 12).

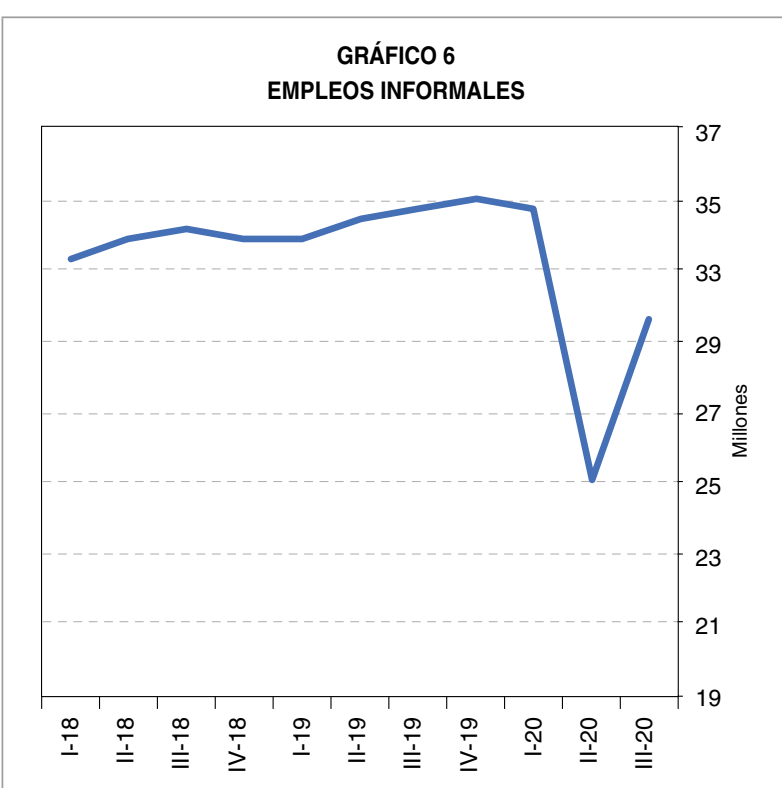

Fuente: INEGI, 2020. IMSS, 2020. BANXICO, 2020. CONEVAL, 2020.

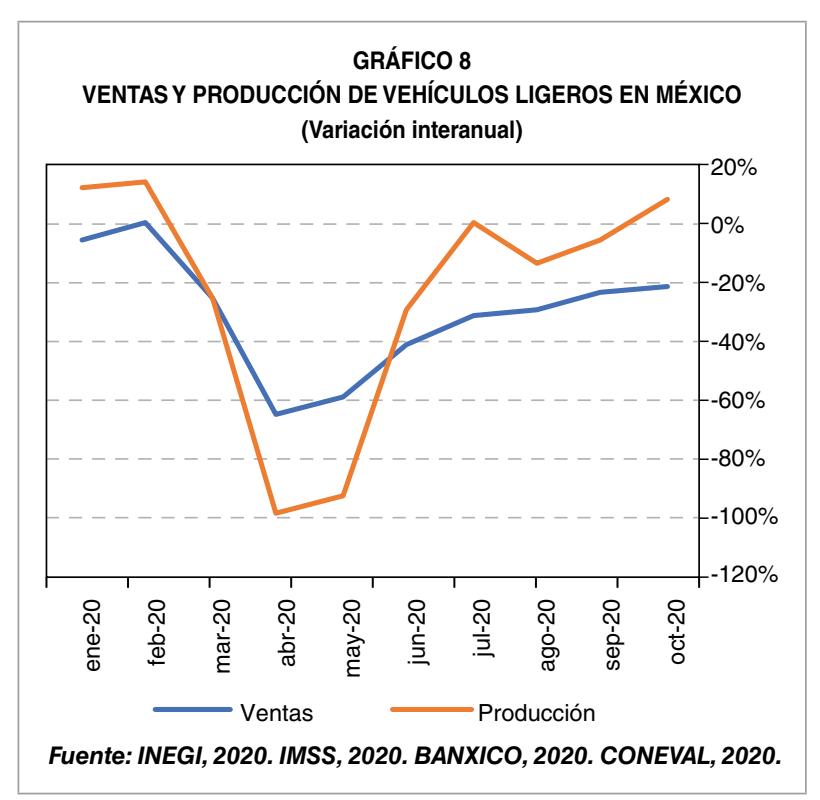



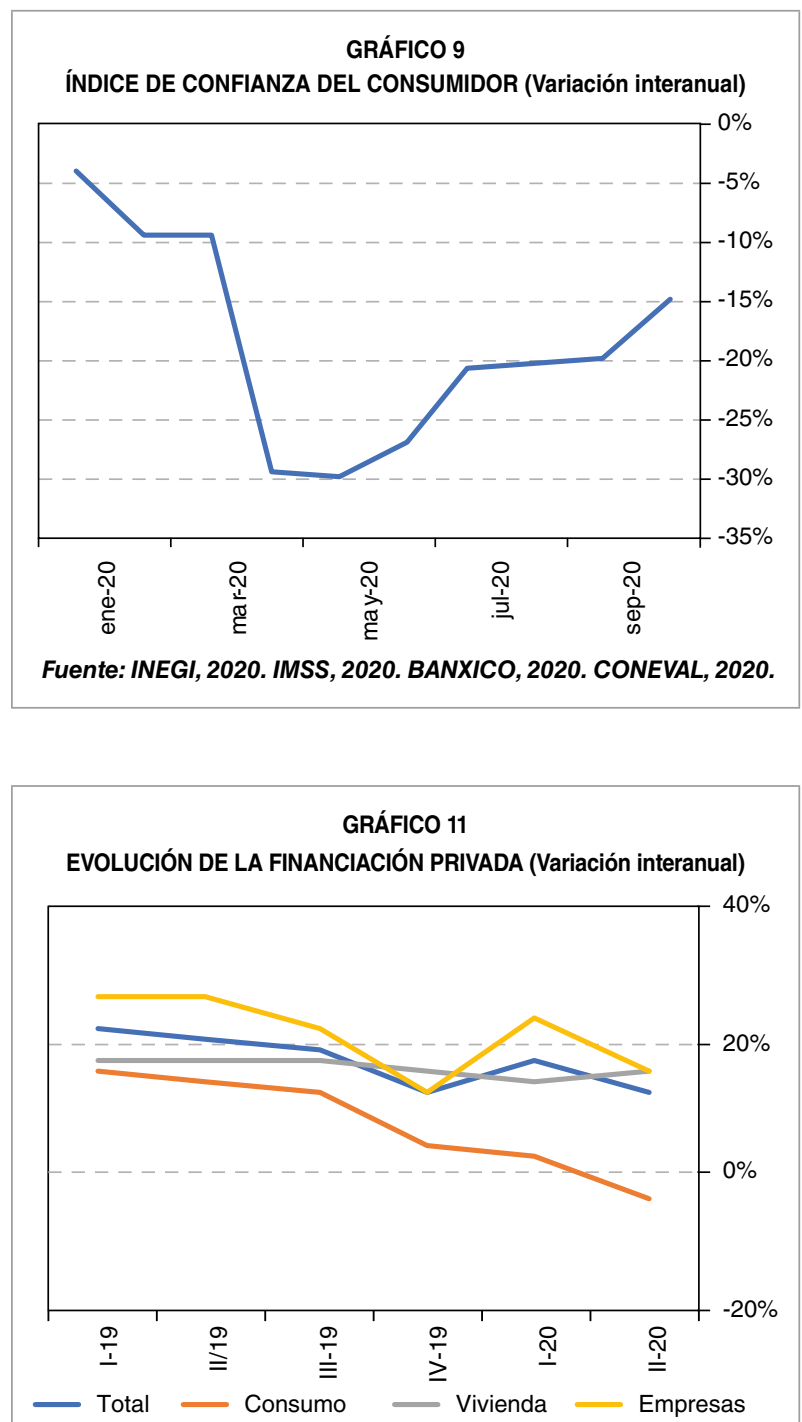

Fuente: INEGI, 2020. IMSS, 2020. BANXICO, 2020. CONEVAL, 2020.

\subsection{Indicadores macroeconómicos}

Antes de analizar los principales indicadores macroeconómicos del país, conviene mencionar que México es la 15. economía más grande del mundo, o la 11. ${ }^{\text {a }}$ si se atiende a su paridad de poder adquisitivo y tiene 128,9 millones de habitantes (FMI, 2020). México cuenta con una economía abierta, en la que la suma de las exportaciones e importaciones representa un $65 \%$ del PIB, y con un importante peso del consumo privado, también del $65 \%$ del PIB. La inversión y el gasto público, en
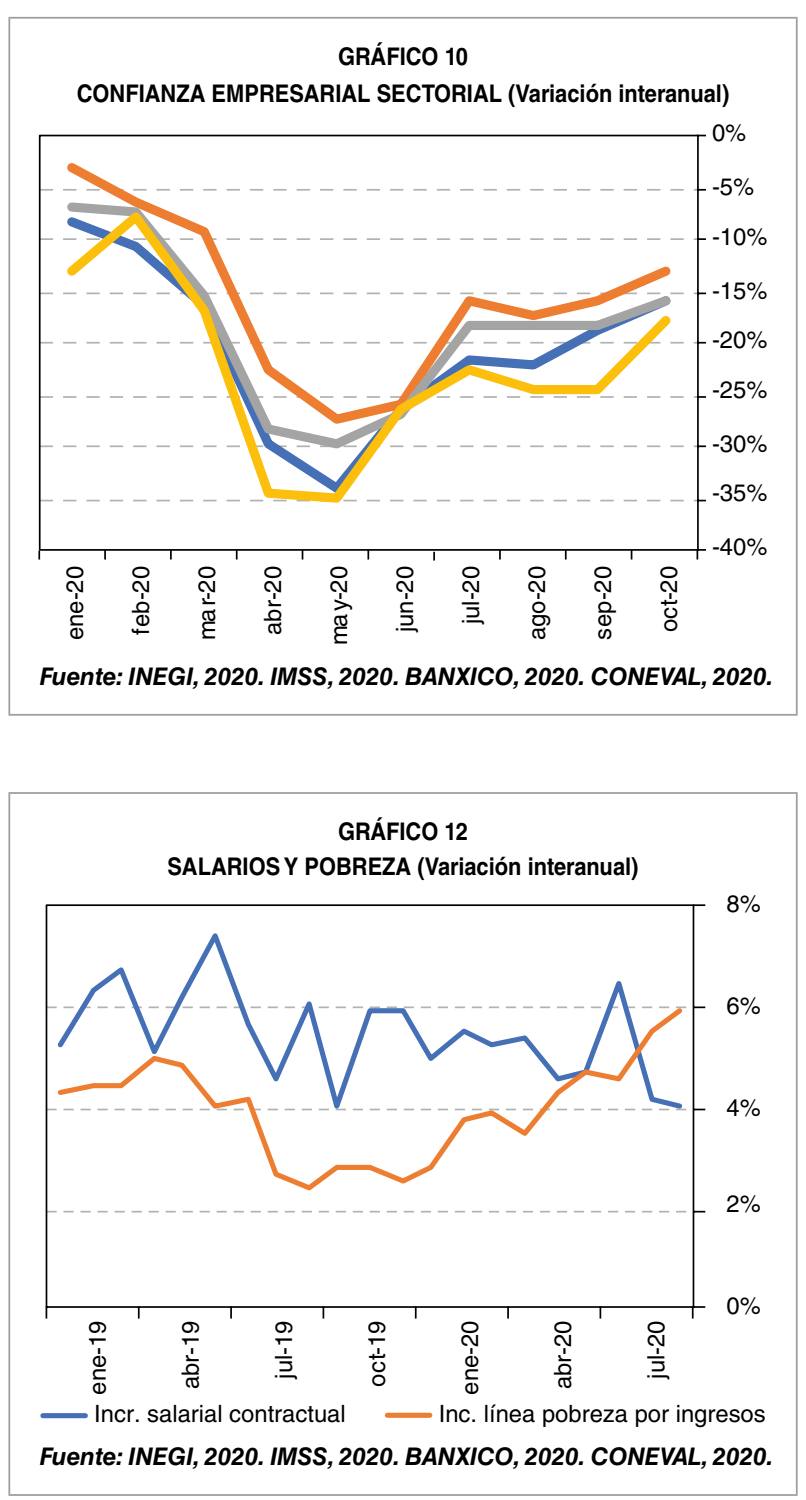

cambio, tienen un peso inferior al de otros países comparables, cada uno del $15 \%$ del PIB respectivamente (INEGI, 2020).

Como se puede observar en el Gráfico 13, a pesar de que la economía venía lidiando con una situación de desaceleración y estancamiento en 2019, el desplome productivo del $18,7 \%$ en el segundo trimestre de 2020 no tiene precedentes. Por componentes, el consumo $(20,6 \%)$ y la inversión (34\%) explican el grueso de la contracción (Gráfico 13). El sector exterior tiene una aportación negativa del 1,05\%, con una mayor contracción de las exportaciones $\triangleright$ 
(30,9\%) que de las importaciones $(29,7 \%)$. El gasto público, en cambio, registra un incremento del $2,41 \%$, generando una aportación positiva del 0,29\% (BANXICO, 2020).

El comienzo de la crisis económica estuvo marcado por una fuerte depreciación del peso, de hasta un $35 \%$, alcanzando así un mínimo histórico de 25,1 pesos mexicanos por cada dólar americano entre los meses de abril y mayo (Gráfico 14). Esta pérdida de valor, derivada de la salida de capitales, fue común a otras monedas de países emergentes, que, en gran medida, se explica por el aumento de la incertidumbre y de la aversión al riesgo globales. Posteriormente, el peso se ha ido recuperando hasta alcanzar una depreciación del $14 \%$ en octubre respecto de febrero (BANXICO, 2020).

Uno de los riesgos que conlleva esta depreciación es el pass-through a los precios. En agosto y septiembre, como resultado tanto del componente subyacente como no subyacente, se han registrado los mayores niveles en la inflación anual desde mayo de 2019, con un $4,05 \%$ y $4,01 \%$ respectivamente, superando así levemente la banda superior objetivo del Banco de México del $4 \%$ (Gráfico 15). El incremento en los precios se puede observar especialmente en alimentos, bebidas, tabaco, frutas y verduras, que presentan una inflación anual superior al $7 \%$ en agosto y septiembre (INEGI, 2020), tendencia que podría incrementar las tasas de pobreza.

La presión inflacionaria ha provocado que el Banco de México haya recortado tipos más lentamente que otros bancos centrales. Así, el tipo de interés ha pasado del $7,25 \%$ en enero al $4,25 \%$ en octubre, para reactivar la economía (Gráfico 16).

Sin embargo, este estímulo, como ya se ha podido observar en la evolución de la concesión de créditos privados, parece no haber tenido tampoco un impacto significativo en la recuperación de la inversión fija bruta, que se sitúa un $21,2 \%$ por debajo de los niveles de 2019 (Gráfico 17). Asimismo, la inversión extranjera directa muestra una caída de un $0,7 \%$ en el primer semestre de 2020 (Gráfico 18), destacando la pérdida de la inversión en el sector de la construcción, entre otros (Secretaría de Estado de Economía de México, 2020). En cuanto al índice de pedidos manufactureros (Gráfico 19), que puede indicar la confianza y tendencia de la actividad económica, se observa cierta recuperación, situándose en los 49,97 puntos, cerca de rebasar el umbral de los 50 puntos y entrar en niveles de expansión.

La Bolsa Mexicana de Valores (Gráfico 20), como reflejo de las expectativas económicas en el futuro, muestra cierto grado de recuperación; sin embargo, la incertidumbre causada por los rebrotes sigue presente. El sector financiero, debido al entorno regulatorio y los bajos tipos de interés, y a pesar de encontrarse bien capitalizado y con bajas tasas de morosidad, es uno de los más afectados. Asimismo, los sectores industriales y de consumo, debido a distintos factores, como las restricciones impuestas a la producción durante la pandemia y a la disminución del gasto privado, muestran caídas notables. El sector de los materiales es el que presenta una mayor recuperación, superando incluso los niveles de principios de este año. El sector salud, por su parte, es el que ha mantenido una mayor estabilidad, principalmente favorecido por el incremento en el gasto para hacer frente a la COVID-19.

Finalmente, mencionar el impacto que tiene la caída del petróleo en la economía mexicana y especialmente en las cuentas públicas del Estado, en las que representa en torno al $20 \%$ de los ingresos fiscales. A pesar de alcanzar un $\triangleright$ 

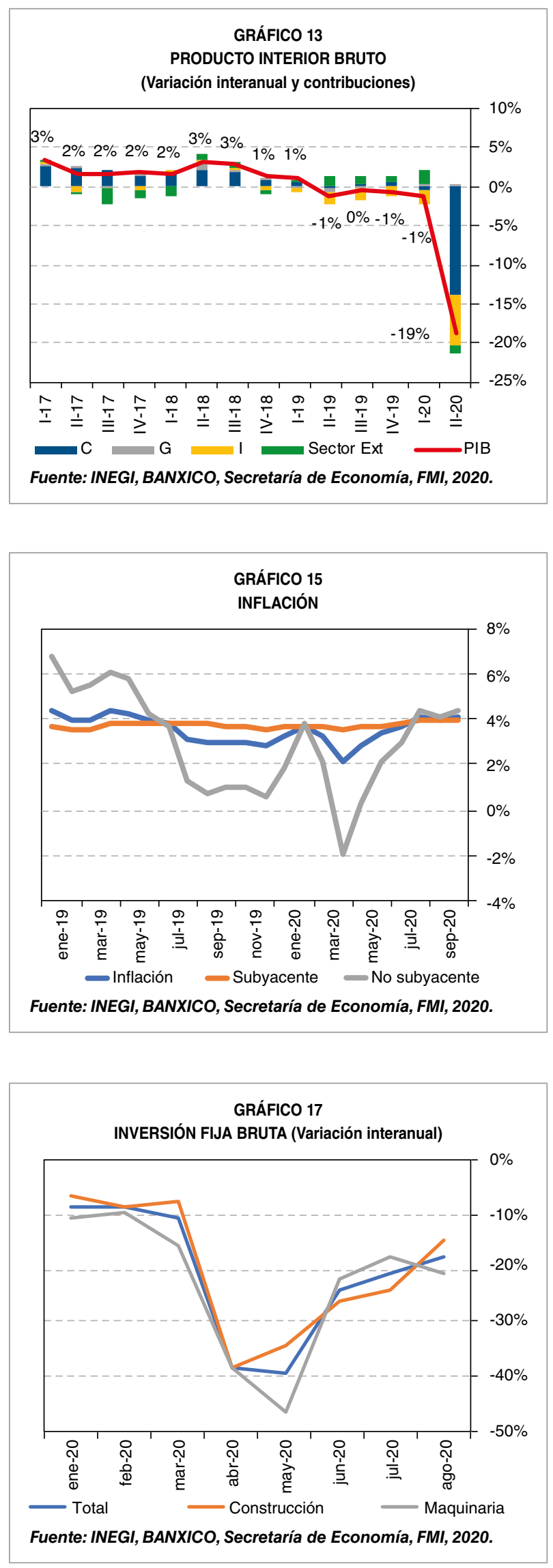

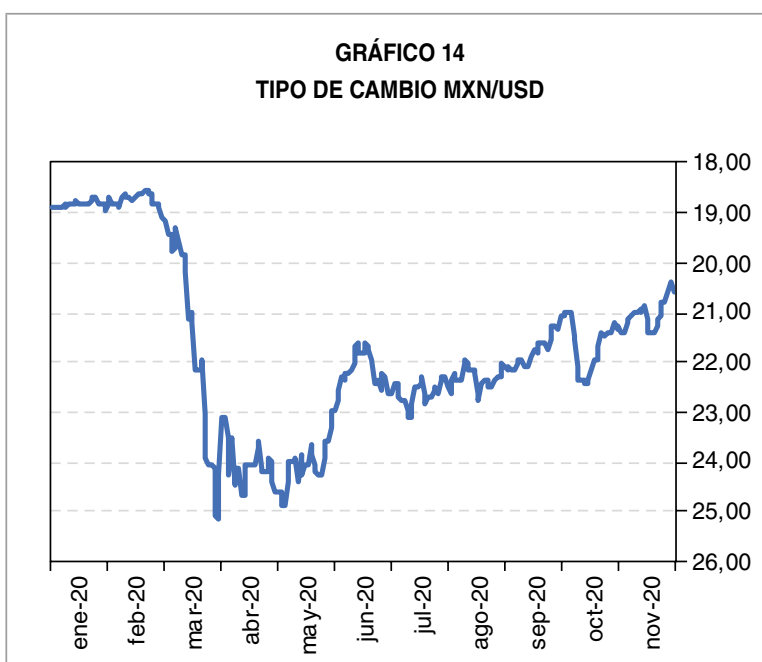

Fuente: INEGI, BANXICO, Secretaría de Economía, FMI, 2020.

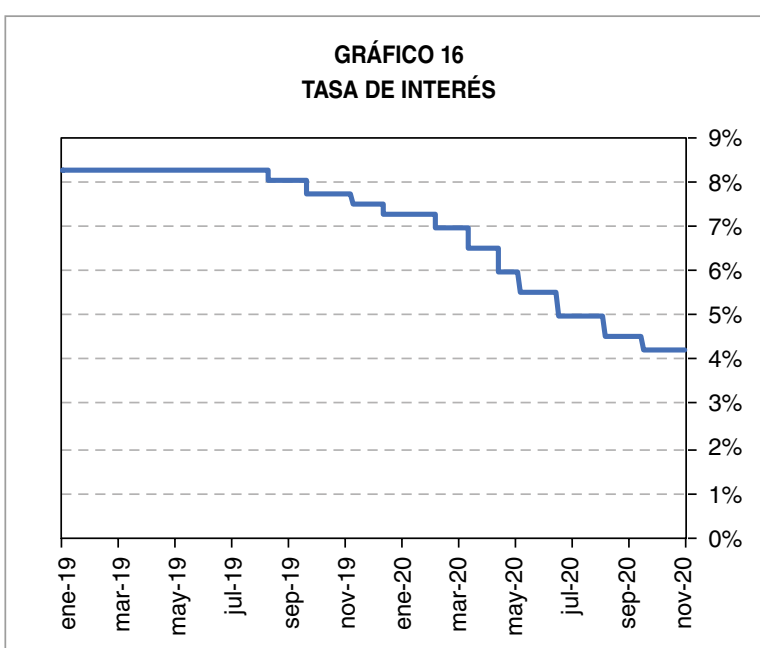

Fuente: INEGI, BANXICO, Secretaría de Economía, FMI, 2020.

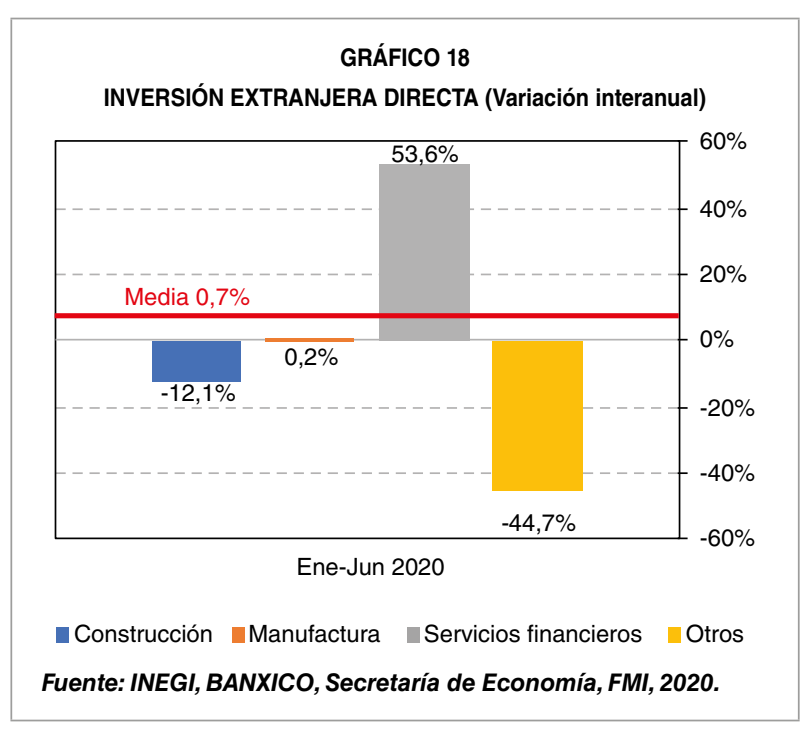



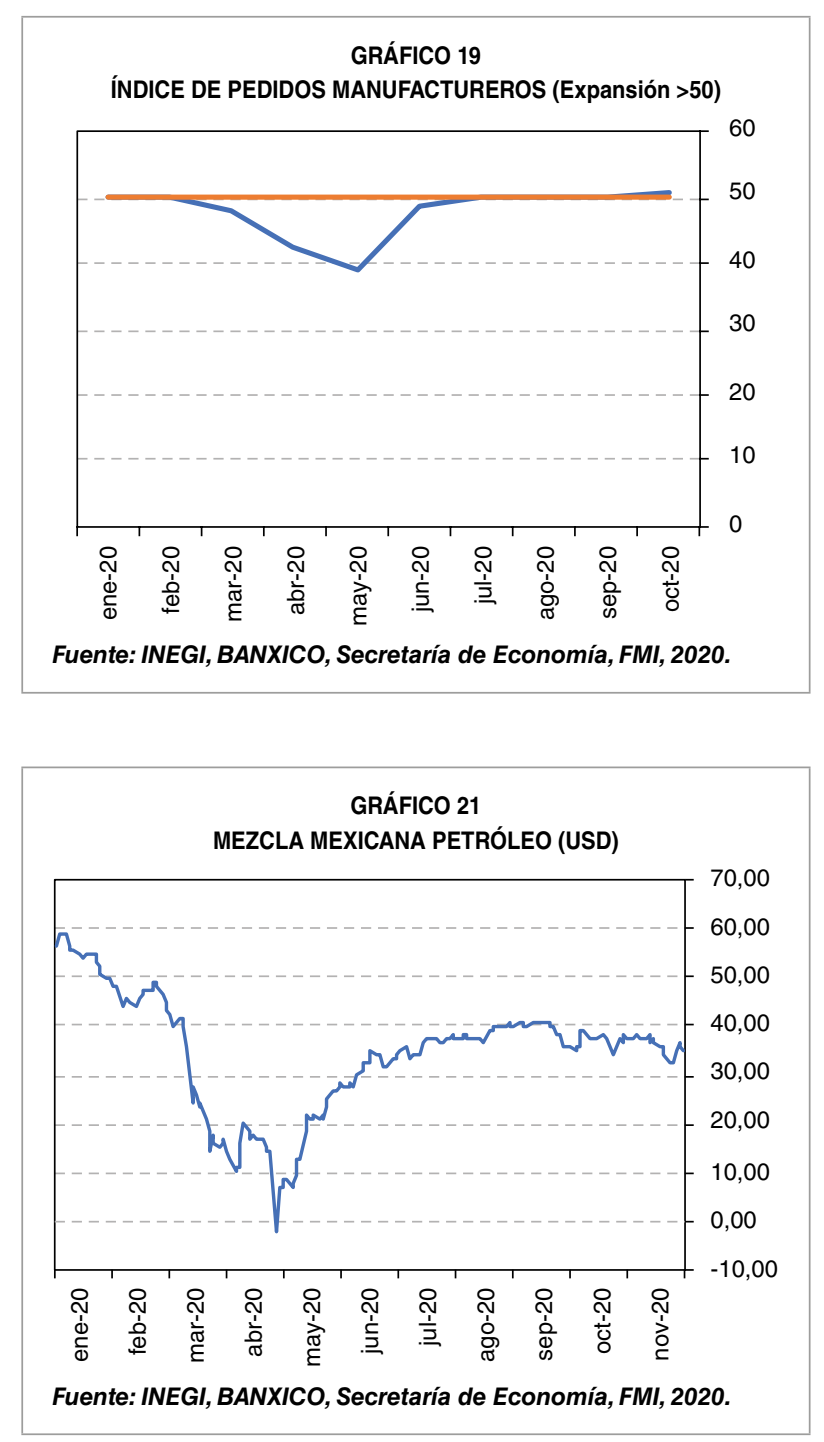

precio negativo durante el mes de abril, la mezcla mexicana se ha recuperado en buena medida, superando los 40 dólares estadounidenses por barril durante septiembre (Gráfico 21). Sin embargo, su contribución a los ingresos públicos es inferior a la esperada en el presupuesto de 2020, en el que se suponía un precio por barril medio para el conjunto del año de 49 USD.

\subsection{Perspectivas sectoriales}

Desde un punto de vista sectorial, hay una caída prácticamente general de los distintos
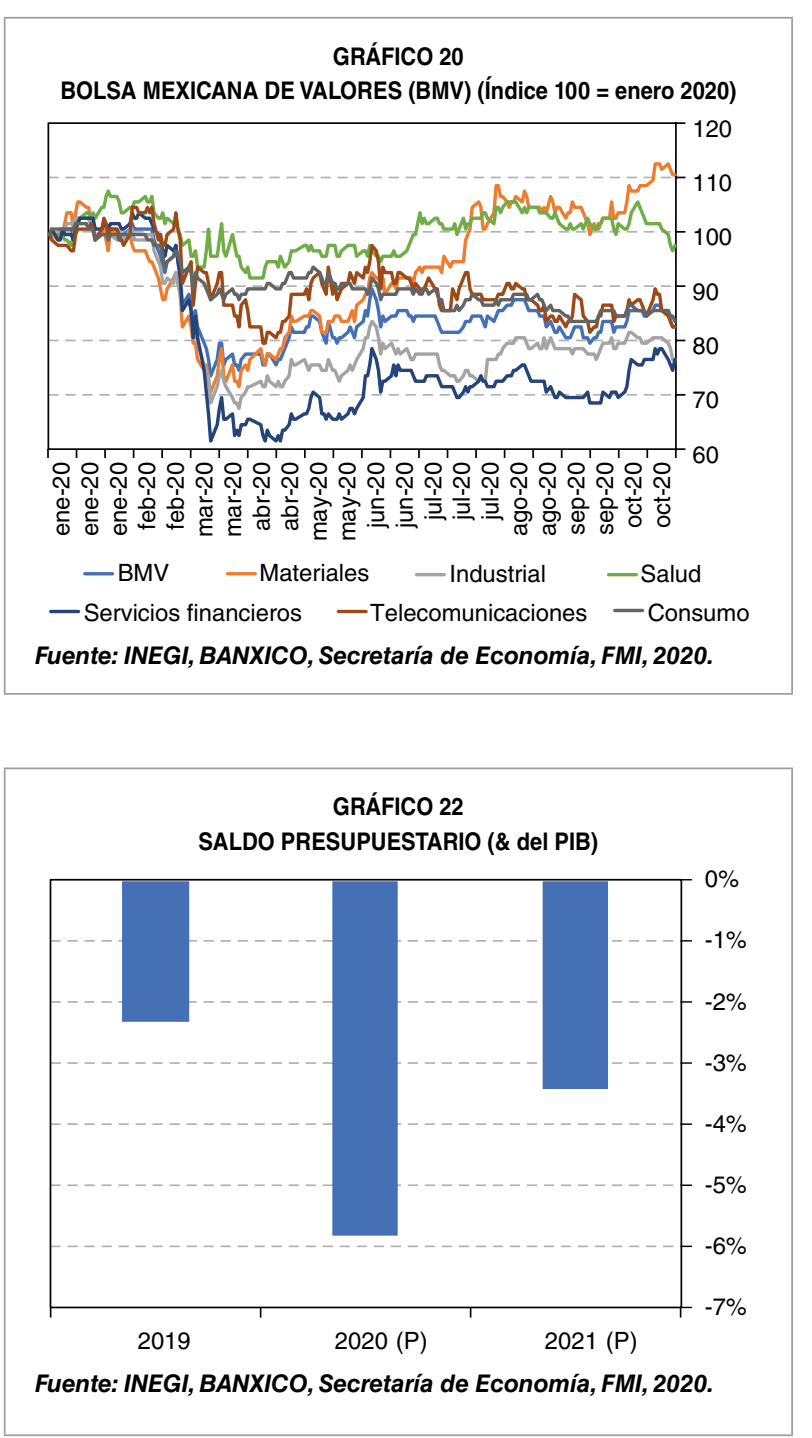

sectores económicos, aunque con grandes diferencias entre ellos. En el Gráfico 23 se representa la evolución de la producción de cada uno de los sectores durante el primer semestre de 2020, así como su previsión anual según BBVA.

Al igual que en el resto del mundo, en México los sectores más afectados por la COVID-19 han sido los servicios de alojamiento temporal, preparación de alimentos y bebidas, y los servicios de esparcimiento culturales, deportivos y recreativos, con una caída en el primer semestre del $39,6 \%$ y $46,7 \%$ respectivamente. Sin embargo, los sectores que más han $\triangleright$ 


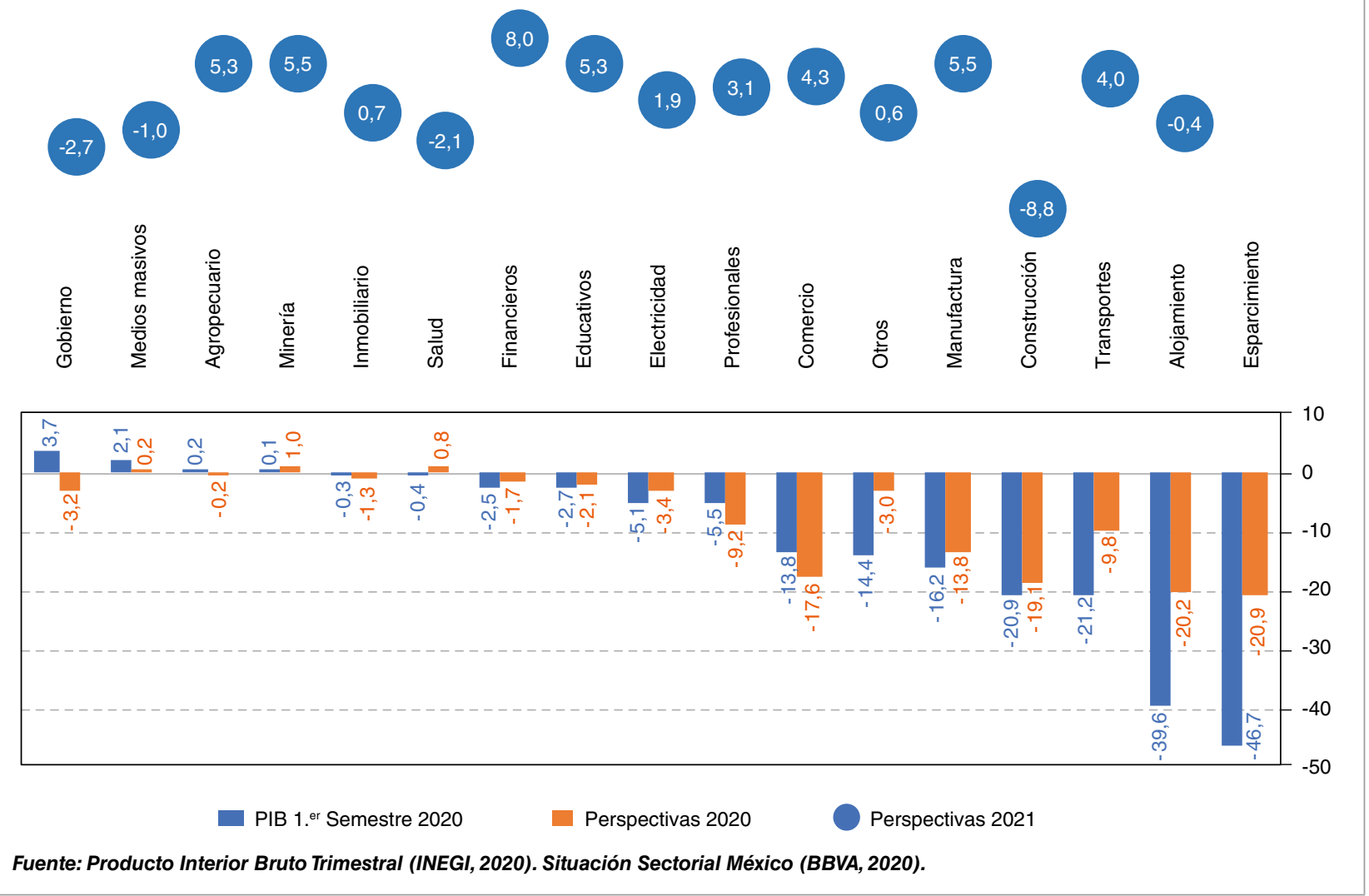

contribuido a la bajada del PIB, debido a su peso en el mismo, son el comercio y las manufacturas, que representan casi la mitad de la caída del PIB en el primer semestre, que se contrajo un 10,5\% (INEGI, 2020). Por otro lado, sectores como la Administración pública, la información en medios masivos, agropecuario y minería, muestran un leve incremento en la producción.

A pesar de que la contracción es generalizada y se estima que la recuperación será lenta, en determinados sectores surgirán oportunidades. Destacan especialmente las relacionadas con el sector de la salud, debido a las crecientes necesidades de medicamentos y material sanitario, el incremento en la demanda de los productos y servicios digitales, sobre todo del comercio electrónico, debido a las medidas de distanciamiento social, y, finalmente, las oportunidades de inversión en el sector de las manufacturas, principalmente en la actividad automotriz, de metálica y bienes de equipo, gracias a la entrada en vigor del nuevo Tratado de México, Estados Unidos y Canadá (T-MEC) en julio de 2020, que podría reforzar la cadena de valor regional. Asimismo, se observan algunos nichos con potencial de crecimiento como las fintech, los servicios de ciberseguridad, los videojuegos o las plataformas de e-learning. 


\subsection{Medidas de política económica}

De forma general, las principales medidas adoptadas por los países están dirigidas a fortalecer los sistemas de salud, apoyar el sustento de los ingresos de los grupos de población más vulnerables, la suspensión de actividades y protección de la población y de los trabajadores, beneficios fiscales, programas de apoyo a las empresas, una política monetaria que asegure la liquidez y una política comercial que controle las exportaciones, especialmente de productos médicos.

Para alcanzar los objetivos anteriores se han adoptado dos tipos de medidas fiscales, presupuestarias y extrapresupuestarias. Las primeras son incrementos de gasto público y alivios tributarios, mientras que las segundas constan principalmente de préstamos y garantías. En el panorama internacional se pueden apreciar distintas posturas a la hora de analizar las respuestas fiscales adoptadas por distintos países, tanto por el tipo de medidas implementadas como por el peso total que representan en el PIB. En México, el conjunto de medidas adoptadas suma un 1,1\% del PIB, mientras que en otros países de América y Europa estos esfuerzos fiscales llegan a superar el $10 \%$ del PIB (Gráfico 24). Este enfoque obedece principalmente al objetivo de las autoridades mexicanas de salvaguardar la estabilidad presupuestaria. Por su parte, la deuda pública se encuentra en niveles sostenibles, en el entorno del $65,5 \%$ (FMI, 2020).

En marzo se pueden observar las primeras reacciones de las autoridades, a destacar la estabilización del tipo de cambio a través del programa de coberturas cambiarias de la Comisión de Cambios y la flexibilización de los criterios para aplazar créditos, amparada por la Comisión Nacional Bancaria y de Valores para la concesión de créditos.

Pero no es hasta abril cuando se adoptan las medidas de estímulo más relevantes. Destaca el apoyo a los servicios de salud, a través de la contratación de 45.000 médicos y $\triangleright$

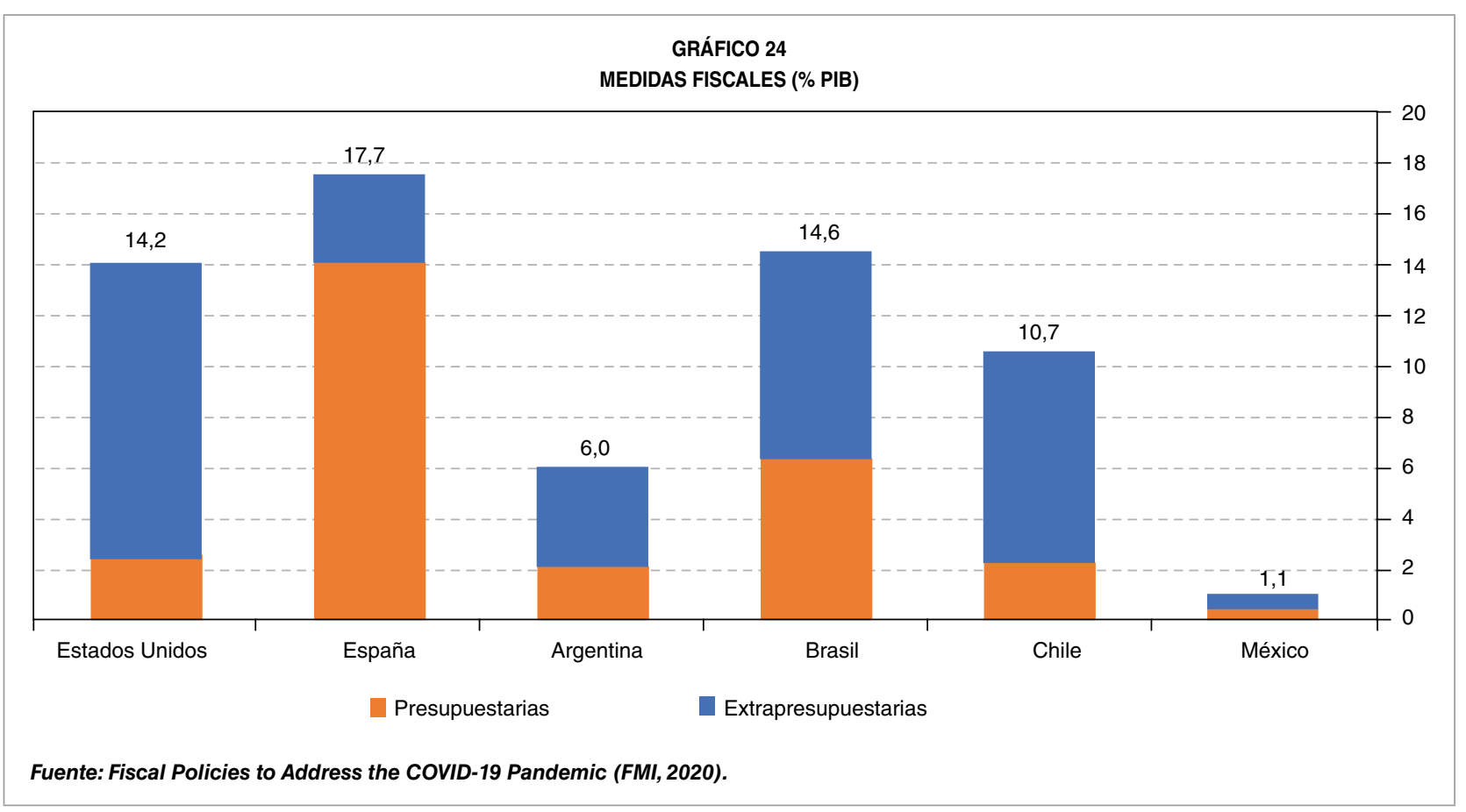


enfermeras, y la ampliación presupuestal para reforzar las medidas de contención, para lo que se destinan 44.500 millones de pesos $(0,18 \%$ del PIB). También hay que resaltar el apoyo a los hogares y empresas $(0,72 \%$ del PIB) para acceder al sistema financiero a través de la concesión de dos millones de créditos de 25.000 pesos (unos 1.000 dólares), a empresas registradas ante el IMSS que no disminuyeron su plantilla laboral y a empresas familiares registradas en los censos de bienestar. Además, se han otorgado facilidades del Instituto del Fondo Nacional de la Vivienda para los Trabajadores (Infonavit) por un total de 20.000 millones de pesos para quienes perdieron su relación laboral a causa de la contingencia. El fondo del Instituto de Seguridad y Servicios Sociales de los Trabajadores del Estado (ISSSTE) ha apoyado a los trabajadores al servicio del Estado y sus familias con alrededor de 35.000 millones de pesos para el otorgamiento de créditos personales. Las autoridades también ampliaron los programas de bienestar para la población más vulnerable y promovieron la construcción de infraestructura social en zonas marginadas. Por último, el Estado central adelantó las transferencias de abril y mayo para gastos en salud, para hacer frente a la situación sanitaria $(0,08 \%$ del PIB).

En lo que a política monetaria se refiere, el Banco de México, además de reducir la tasa de interés del $7,25 \%$ al $4,25 \%$, adoptó una serie de medidas para asegurar la estabilidad financiera y facilitar el crédito. Para ello se ha disminuido el depósito de regulación monetaria, lo que equivale a un menor requerimiento de reserva, y se ha reducido la tasa de interés de la Facilidad de Liquidez Adicional Ordinaria, lo que ofrece liquidez con un menor coste a las instituciones de banca. Además, se han provisto recursos a instituciones bancarias para canalizar el crédito especialmente hacia las pymes. También se ha ampliado el programa de coberturas cambiarias, se han realizado subastas de crédito en dólares estadounidenses y se han establecido coberturas cambiarias liquidables por diferencia horaria en dólares estadounidenses para operar en los horarios en los que los mercados están cerrados. El total de la suma de medidas financieras adoptadas por el Banco de México es equivalente al 3,3\% del PIB. No obstante, de acuerdo con el Fondo Monetario Internacional (FMI), el uso de estas facilidades ha sido limitado, lo que refleja, en parte, que los grandes corporativos han mantenido el acceso al mercado $y$, en parte, el escaso apetito de los bancos comerciales por prestar a las pymes sin aval suficiente.

\section{Perspectivas}

La incertidumbre, tanto en el plano sanitario como en el económico, ha alcanzado unos niveles desconocidos hasta la fecha. Esto se pone de manifiesto con las intensas revisiones en las previsiones de actividad (Gráfico 25). Así, mientras la Encuesta sobre las Expectativas de los Especialistas en Economía del Sector Privado del Banco de México, en marzo, estimaba una caída del PIB del $4 \%$ en 2020 , en la última encuesta, realizada en octubre de 2020, apunta una caída del PIB del 9,4\%. De igual manera, el Fondo Monetario Internacional estimaba en abril una caída del $6,6 \%$ del PIB en 2020 en México, mientras que en su informe de octubre apuntó una caída mayor, del $9 \%$, aunque inferior al $10,5 \%$ previsto en junio. Por su parte, el Banco de México ha optado por capturar esta incertidumbre con un rango de previsiones bajo diferentes supuestos, que oscilan para 2020 entre el $-8,8 \%$ y el $-12,8 \%$. $\quad \triangleright$ 


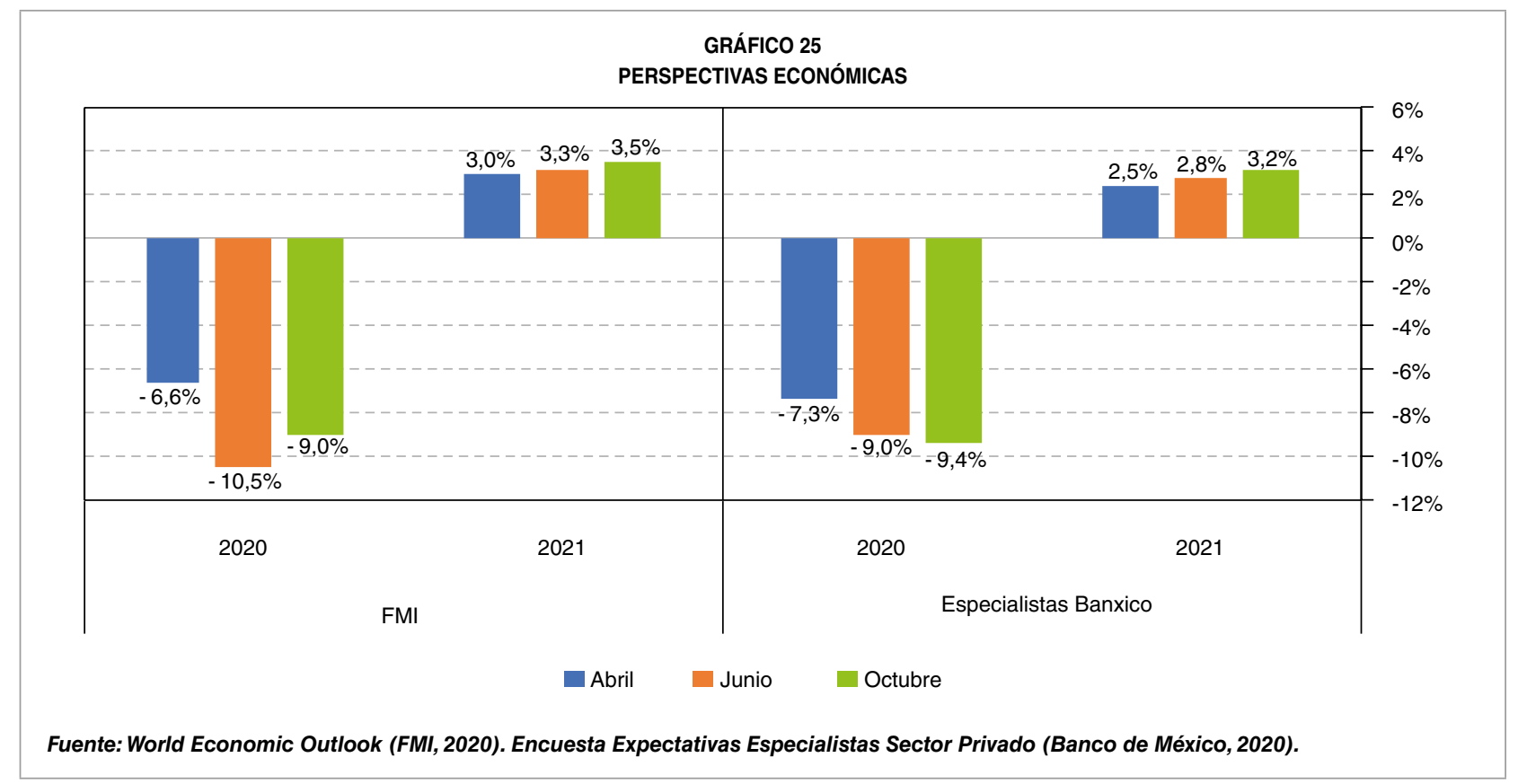

A pesar de la escasa adopción de nuevas políticas fiscales en comparación con otros países, la economía mexicana ha rebotado con fuerza en el tercer trimestre, aunque se está frenando en el cuarto ante la dificultad de controlar la pandemia en América y Europa. Las nuevas medidas de confinamiento son menos restrictivas y más focalizadas que antes. Pero, en todo caso, es difícil volver a los niveles de movilidad precrisis sin una vacuna aprobada.

Para 2021, tanto el FMI como el consenso de analistas esperan una recuperación superior al $3 \%$. Hay que destacar que este repunte se apoya, en gran medida, en el crecimiento de EE UU, mercado que representa el $80 \%$ de las exportaciones de México y el $47 \%$ de la inversión extranjera directa en México. El nuevo Tratado entre México, Estados Unidos y Canadá (TMEC), posiblemente, aumentará esta interdependencia. Asimismo, los principales analistas esperan una política monetaria acomodaticia, con tipos de interés reales próximos a cero, que ayudarán a afianzar la recuperación. En el plano fiscal, se espera un apoyo más tímido.
Como vimos, por sectores, la mayor aportación se espera en los sectores agropecuario, minero, de servicios financieros, educación y manufacturas, todos ellos con una perspectiva de crecimiento superior al $5 \%$ en 2021.

\section{Conclusión}

México ha sido golpeado por la crisis en un momento de crecimiento anémico (contracción del 0,3\% en 2019). Las medidas de contención adoptadas han desencadenado una profunda recesión en el segundo trimestre del año, sin que se hayan visto compensadas suficientemente por políticas de estímulo. No obstante, desde que comenzara la reapertura en junio se ha observado una patente reactivación de todos los indicadores de coyuntura, que se ha visto confirmada con la buena cifra del tercer trimestre.

En todo caso, México cuenta con fortalezas que permiten aventurar una intensa recuperación en 2021. Desde una perspectiva $\square$ 
externa, se espera que el nuevo TMEC proporcione un importante estímulo al país, fruto de una intensificación de los flujos comerciales y financieros con EE UU y Canadá. La próxima firma del Tratado de Libre Comercio entre México y la Unión Europea (TLCUEM), prevista para 2021, también podría contribuir al impulso exterior. Desde una perspectiva interna destacan los buenos fundamentos macroeconómicos de partida, que dotan de margen de intervención a las autoridades, si fuese necesario. En todo caso, la aplicación de políticas económicas que tiendan a promover la inclusión social, especialmente en el mercado de trabajo, y a mejorar el clima inversor, va a ser crucial para apuntalar el crecimiento de los próximos años.

\section{Bibliografía}

BANXICO (Banco de México) (2020a). Bolsa Mexicana de Valores. https://www.banxico.org.mx/ Sielnternet/consultarDirectoriolnternetAction.do?

BANXICO (Banco de México) (2020b). Encuesta sobre las Expectativas de los Especialistas en Economía del Sector Privado (varias). https:// www.banxico.org.mx/

BANXICO (Banco de México) (2020c). Financiamiento interno al sector privado no financiero. https://www.banxico.org.mx/apps/gc/financiamiento-sector-privado.html

BANXICO (Banco de México) (2020d). Indicadores de oferta y demanda agregadas. https://www. banxico.org.mx/Sielnternet/consultarDirectoriolnternetAction.do?

BANXICO (Banco de México) (2020e). Inflación. https://www.banxico.org.mx/Sielnternet/consultarDirectoriolnternetAction.do?

BANXICO (Banco de México) (2020f). Políticas económicas consideradas en México para enfrentar el panorama adverso generado por
COVID-19. https://www.banxico.org.mx/publicaciones-y-prensa/informes-trimestrales/recuadros/\%7B455A13D4-524F-84CE-704E-8045 ED092A0C\%7D.pdf

BANXICO (Banco de México) (2020g). Precio de la mezcla mexicana de petróleo. https://www. banxico.org.mx/apps/gc/precios-spot-del-petroleo-gra.html

BANXICO (Banco de México) (2020h). Revisión de salarios contractuales. https://www.banxico.org. $\mathrm{mx} /$ Sielnternet/consultarDirectoriolnternetAction. do? accion $=$ consultarCuadro \&idCuadro= CL10\&sector $=10 \&$ locale $=e s$

BANXICO (Banco de México) (2020i). Tasa de Interés. https://www.banxico.org.mx/Sielnternet/consultarDirectoriolnternetAction.do?

BANXICO (Banco de México) (2020j). Tipos de cambio diarios. https://www.banxico.org. mx/ Sielnternet/consultarDirectorioInternetAction. do? sector $=6 \&$ accion $=$ consultarCuadro\&idCua$\mathrm{dro}=\mathrm{CF} 102 \&$ locale $=\mathrm{es}$

BBVA (2020). Situación Regional Sectorial México. Segundo semestre 2020. https://www.bbvaresearch.com/publicaciones/situacion-regionalsectorial-mexico-segundo-semestre-2020/

CONEVAL (Consejo Nacional de Evaluación de la Política de Desarrollo Social) (2020). Evolución de la líneas de pobreza por ingresos. https:// www.coneval.org.mx/Medicion/MP/Paginas/Lineas-de-bienestar-y-canasta-basica.aspx

DOF (Diario Oficial de la Nación) (2020a). Acciones extraordinarias para atender la emergencia sanitaria generada por el virus SARS-CoV2. https://dof.gob.mx/nota_detalle.php?codigo= 5590914\&fecha $=31 / 03 / 2020$

DOF (Diario Oficial de la Nación) (2020b). Estrategia para la reapertura de las actividades. https://dof.gob.mx/nota_detalle.php?codigo= 5593313\&fecha $=14 / 05 / 2020$

FMI (Fondo Monetario Internacional) (2020a). Fiscal Monitor: Policies for the Recovery. https:// $\square$ 
www.imf.org/en/Publications/FM/Issues/2020/ 09/30/october-2020-fiscal-monitor

FMI (Fondo Monetario Internacional) (2020b). México: 2020 Artículo IV. https://www.imf.org/ en/Publications/CR/Issues/2020/11/03/ Mexico-2020-Article-IV-Consultation-Press-Release-and-Staff-Report-49863

FMI (Fondo Monetario Internacional) (2020c). Perspectivas de la economía mundial (varias). https://www. imf.org/es/Publications/WEO/Issues/2020/09/30/ world-economic-outlook-october-2020

Google LLC (2020). Google COVID-19 Community Mobility Reports. https://www.google.com/covid19/mobility/index.html?hl=en

IMSS (Instituto Mexicano del Seguro Social) (2020). Puestos de trabajo afiliados al seguro social. http://www.imss.gob.mx/conoce-al-imss/cubos

INEGI (Instituto Nacional de Estadística y Geografía) (2020a). Comercio. https://www.inegi.org.mx/ temas/comercioemp/default.html\#Informacion _general

INEGI (Instituto Nacional de Estadística y Geografía) (2020b). Confianza del consumidor. https:// www.inegi.org.mx/temas/confianza/

INEGI (Instituto Nacional de Estadística y Geografía) (2020c). Confianza empresarial. https://www. inegi.org.mx/temas/opinion/

INEGI (Instituto Nacional de Estadística y Geografía) (2020d). Encuesta Nacional de Ocupación y Empleo (ENOE). https://www.inegi.org.mx/programas/enoe/15ymas/

INEGI (Instituto Nacional de Estadística y Geografía) (2020e). Encuesta Telefónica de
Ocupación y Empleo (ETOE). https://www.inegi. org.mx/investigacion/etoe/

INEGI (Instituto Nacional de Estadística y Geografía) (2020f). Inversión fija bruta. https://www. inegi.org.mx/temas/ifb/

INEGI (Instituto Nacional de Estadística y Geografía) (2020g). Pedidos manufactureros. https:// www.inegi.org.mx/temas/pedidosman/

INEGI (Instituto Nacional de Estadística y Geografía) (2020h). Producto interior bruto. https:// www.inegi.org.mx/temas/pib/\#Informacion_ general

INEGI (Instituto Nacional de Estadística y Geografía) (2020i). Registro administrativo de la industria automotriz de vehículos ligeros. https://www. inegi.org.mx/datosprimarios/iavl/

Leska, A., y Casaburi, G. (2020). Problemas en la Fábrica: COVID-19. BID. https://blogs.iadb.org/ innovacion/es/covid-19-un-cisne-negro-paralas-cadenas-de-valor/

Secretaría de Economía del Gobierno de México (2020). Inversión extranjera directa. https://www. gob.mx/se/acciones-y-programas/competitividady-normatividad-inversion-extranjera-directa?state=published

Unión Europea (2020). Portal de datos abiertos de la UE: Datos de la enfermedad de COVID-19. https://data.europa.eu/euodp/es/data/dataset/ covid-19-coronavirus-data

Universidad de Oxford (2020). Coronavirus Government Response Tracker. https://www.bsg.ox. ac.uk/research/research-projects/coronavirusgovernment-response-tracker 
